Trab. Ling. Aplic., Campinas, 44(2): 185-199, Jul./Dez. 2005

\title{
A CONTRIBUIÇÃO CHOMSKIANA PARA A COMPREENSÃO DA APRENDIZAGEM DE L2
}

\author{
MARY A. KATO \\ (Unicamp)
}

Ao John,

que um dia foi chomskiano

\begin{abstract}
RESUMO
Este trabalho procura mostrar as contribuições de Chomsky para a área da psicolingüística, mais diretamente para explicar a aquisição de L1, e indiretamente para levantar questões de pesquisa em L2. Pode-se dizer que Chomsky contribuiu, primeiramente, ao argumentar contra outras abordagens, mas, sobretudo, por a) propor uma teoria sobre as línguas que dá conta de seus princípios universais e de seus parâmetros de variação e b) demonstrar que a teoria é diretamente relevante para as questões de aprendizagem e mais interessante do que a visão behaviorista e a construtivista piagetiana. O presente trabalho apresenta, a seguir, as teorias sobre L2 que surgiram a partir do modelo chomskiano.
\end{abstract}

Palavras chave: Chomsky, aprendizagem, L2.

\section{ABSTRACT}

This paper tries to show Chomsky's contributions to the area of psycholinguistics, more directly to explain first language acquisition, and less directly to raise questions regarding research in L2. Chomsky can be said to have contributed first by arguing against the current views on language learning, but also and mainly a) for his proposal of a theory of natural languages that accounts both for their invariant principles, but also for their crosslinguistic variation, and b) for showing that such theory is directly relevant to explain language acquisition problems, and more interesting than the behaviorist or constructionist views. The last part presents the theories about L2 acquisition derived from Chomsky's theories on language.

Key-words: Chomsky, learning, second language.

\section{INTRODUÇÃO}

É do conhecimento geral que, após um entusiasmo inicial pelas possibilidades de uso da teoria gerativa ao ensino/aprendizagem ${ }^{1}$ de $\mathrm{L} 2$, houve um ceticismo crescente, na década de 70, em relação à aplicabilidade da perspectiva chomskiana para resolver questões de

\footnotetext{
${ }^{1}$ Estou usando o termo aprendizagem como equivalente a "learning", neutro em relação à dicotomia entre aquisição e aprendizagem em português.
} 
KATO - A contribuição Chomskiana...

aprendizagem de L2. Esse ceticismo culmina, com uma redefinção dos objetivos e domínios da lingüística aplicada, identificada inicialmente com L2 mais do que com L1. Para muitos, os objetivos e domínios da "nova" lingüística aplicada é transdisciplinar, fugindo ao domínio estrito da lingüística. (cf. Celani \& Pascoal, 1992, Introdução e Parte 1)².

É bastante compreensível porque tal descrédito ocorreu. Primeiro, porque Chomsky inicialmente colocou a questão do uso em segundo plano, com a dicotomia "competência" e "performance". Em segundo lugar, porque o conceito de transformação foi tomado pelos psicolingüistas como um processo psicológico e não como uma regra abstrata, e os resultados, obviamente, não foram os esperados. Em terceiro, porque a década foi totalmente dedicada aos Princípios, que regem "todas" as línguas naturais. Esses Princípios compreenderiam as propriedades das línguas humanas geneticamente determinadas e que prescindiriam de aprendizagem. Obviamente o lingüista interessado em aprendizagem não está interessado em propriedades que não precisam ser aprendidas, mas naquelas que exigem aprendizagem, justamente por não ser uma propriedade invariante das línguas naturais. Mas o importante é entender suas propostas da década de setenta como uma fase de seu programa de pesquisa, e perguntar-se hoje qual a possível contribuição de Chomsky, em seu trajeto, para questões de ensino/aprendizagem de línguas.

O objetivo deste artigo é lembrar, contra esse ceticismo, as contribuições de Chomsky, como epistemólogo, para as questões de aquisição lingüística e mostrar o alcance de sua teoria para a compreensão do que ocorre na aprendizagem de uma L2. É possível dizer que nenhuma abordagem, hoje, ousaria afirmar que a aquisição da lingua é uma função estritamente da instrução, isto é, da estimulação do meio. Sabe-se atualmente que, para um organismo interagir com o meio, ele requer um mínimo de estrutura interna. A questão, então, recai sobre a natrureza da estrutura da mente/cérebro responsável pela aquisição de uma língua natural qualquer. Veremos, neste trabalho, os diálogos de Chomsky com Skinner e com Piaget sobre as respectivas visões sobre essa estrutura interna. Com o primeiro, através de sua resenha (Chomsky, 1959) do behaviorismo, e com o segundo, através de um debate organizado por Piattelli-Palmarini (1980). Isso nos possibilitará ter um entendimento melhor da proposta chomskiana.

Na seção 2, farei uma discussão geral sobre as concepções sobre língua e as perspectivas sobre a sua aprendizagem. Na seção 3, mostrarei o impacto da resenha de Chomsky do livro Verbal Behavior de B.F. Skinner e as críticas principais de Chomsky às idéias de Piaget. Na seção 4 descreverei, em linhas gerais, a proposta de aprendizagem em Chomsky, no modelo de Princípios e Parâmetros. Na seção final, veremos o alcance que sua teoria vem tendo para uma compreensão do que ocorre em aprendizagem de L2.

\section{CONCEPÇÕES SOBRE LÍNGUA E SUA APRENDIZAGEM}

A filosofia, a psicologia e a lingüística vem há muito se ocupando da questão da aquisição da linguagem pela criança, questão essa formulada de formas diferentes conforme a perspectiva

\footnotetext{
${ }^{2}$ No exterior, tendência semelhante se verificou, como pode ser visto em Newmeyer,1983; 5.3.
} 
Trab.Ling.Aplic., Campinas, 44(2) - Jul./Dez. 2005

adotada. Na lingüística moderna estruturalista, profundamente afetada pela psicologia behaviorista e pela sociologia de Durkheim, a língua, embora passível de descrição estrutural, é vista, no que diz respeito à aquisição, como um objeto em uso e, como tal, observável em suas manifestações comportamentais em contexto. $\mathrm{O}$ "input" que este fornece à criança é considerado suficientemente rico e dispensa qualquer noção bioprogramada de princípios inatos.

A visão funcionalista desenvolve-se, posteriormente, na linguística e na psicolingüística, em duas direções distintas: a) a sócio-funcionalista, que atribui a ampliação do conhecimento lingüístico às necessidades comunicativas da interação social (Halliday, 1975; G.Sankoff \& Brown, 1976, entre outros) e b) a psico-cognitivista, que atribui a forma da língua a restrições de processamento (Bever,1970, entre outros). A aquisição, nessa perspectiva, é vista como um aumento na capacidade de analisar o "input" (Slobin, 1980), um "parser" cada vez mais potente e eficiente. Diferentemente do estruturalismo e do funcionalismo social, o psico-cognitivismo é mentalista e aborda o dispositivo de aprendizagem em uma linha semelhante à de Piaget. Mas enquanto Piaget atribui a aquisição de qualquer conhecimento a uma inteligência sensório-motora, não especializada, que coordena a atividade estruturadora das ações e das percepções, os lingüistas cognitivistas propõem que o ser humano vem dotado de um módulo específico, com mecanismos específicos para a aprendizagem da língua. Tanto Piaget na psicologia, quanto Slobin na lingüística atribuem o desenvolvimento da capacidade de processar a informação como decorrente da maturação e da experiência.

A linha formalista chomskiana é, desde sua origem, inatista, estruturalista e cognitivomentalista. Porém, ao invés de investigar como os enunciados estruturalmente descritos se prestam para a comunicação ou como eles retratam a nossa forma de processar a informação ${ }^{3}$, Chomsky procura desenhar a arquitetura da mente capaz de produzir as estruturas de uma determinada língua, isto é, tenta desvendar a natureza do conhecimento de um adulto falante de uma língua L, ao que ele denomina língua-I (Individual, Interna e Intensional). É Interna porque nada tem a ver com um objeto no mundo externo, mas com sua representação mental; é Intensional, porque o conhecimento não se deve a um conjunto extensional de sentenças, mas a propriedades que as definem, tratando-se, portanto, de uma visão intensional de conjunto; e é Individual, porque não vê língua como um objeto social, político ou geográfico. O objeto de estudo que se contrapõe ao seu Chomsky chama de língua-E (Externa, Extensional). A Língua-I se compara à concepção que temos de um triângulo, que é intensional definida por propriedades abstratas e a Língua-E aos objetos no mundo, que, embora não exatamente idênticos entre si, identificamos como triângulos.

Seu segundo objetivo é responder como a criança, a partir de um estado inicial $\mathrm{S}_{\mathrm{o}}$ chega a esse conhecimento. Mas antes de passarmos para sua visão de aprendizagem lingüística, vejamos a sua contribuição ao expressar o que ele acredita não serem perspectivas cabíveis de explicar o problema lógico da aqusição.

${ }^{3}$ Cf. Lopes (2001) para uma visão atualizada das idéias de Chomsky sobre o assunto. 
KATO - A contribuição Chomskiana...

\section{CHOMSKY vs SKINNER E CHOMSKY vs PIAGET}

Embora a fase inicial da teoria chomskiana tenha frustrado os psicolinguistas em suas tentativas bem-intencionadas de aplicação para explicar o problema da aquisição da linguagem, eles deveriam ao menos reconhecer o mérito inegável de Chomsky, que, ao resenhar Skinner (1957) e seu monumental trabalho Verbal Behavior ${ }^{4}$, acabou por desacreditar a visão behaviorista da aprendizagem, dominante na época. Outros atribuem esse papel não apenas à resenha, mas à própria visão de língua que Chomsky introduzia. Segundo Judith Greene (apud Newmeyer,1983: 130):

\footnotetext{
"Chomsky's theory of generative transformational grammar was the first to force psycholinguists to reconsider their whole approach to the study of language behavior, and so heralded the psycholinguistic 'revolution"”.
}

Skinner, como sabemos minimizava o papel do aprendiz e do seu organismo e maximizava o papel do estímulo, ou "input", ou do provedor deste. Essa e outras perspectivas associacionistas acreditam que quando um estímulo ambiental $x$ está presente, ele tende a provocar uma resposta $y$, se esta levar a um reforço positivo. O reforço de uma resposta particular generaliza a resposta para um conjunto maior de instâncias de estímulos. Assim, se uma criança repete a palavrs иаи-иаи, produzida por um adulto frente a um cachorro e recebe aplauso ou confirmação, ela pode generalizar a mesma palavra frente a outros cachorros. A generalização se apoia em indução e esta é complementada com abstração, que consiste na emissão da palavra uau-uau na ausência de um cachorro.

Essa explicação fundamentada nas noções de estímulo e resposta é contestada por Chomsky em sua resenha, através de inúmeros exemplos simples e concretos. Diz ele, por exemplo, que Skinner não explica como ele, Chomsky, aprendeu as palavras Eisenhower e Moscou se ele nunca foi exposto a eles qua estímulos. Outro exemplo que ele dá é com relação às respostas "vermelho" ou " cadeira", que podem ser dadas frente a uma cadeira vermelha. A resposta dada é que define o que serviu de estímulo e não o inverso, e a resposta tem a ver com uma atividade mentalista do sujeito e não apenas com o objeto presente. Ele critica igualmente o conceito de reforço, em especial o conceito de autoreforço. Assim, para Skinner, da mesma forma que o músico, ao se ouvir tocar, obtém reforço para seu desempenho, o bebê obtém auto-reforço ao balbuciar sons que ele escutou em seu ambiente. Para Chomsky, Skinner aborda muito pouco os problemas de aprendizagem de língua, stricto sensu, procurando apenas estender o que fez experimentalmente com outras aprendizagens ao problema da aquisição lingüítica. De qualquer forma essa comparação e extensão só são possíveis porque, para Skinner, não há nada de especial na aprendizagem lingüística, em relação às outras aprendizagens.

A maioria das críticas de Chomsky são válidas e certamente ajudaram a mudar, no país e no exterior, o quadro então vigente de ensino/aprendizagem de línguas, pautado na repetição, reforço e correção. Mas é importante ter em conta também que a visão

\footnotetext{
${ }^{4}$ Cf. Chomsky, 1959.
} 
Trab.Ling.Aplic., Campinas, 44(2) - Jul./Dez. 2005

associacionista apresenta, na década de 70, propostas interessantes tanto no nível de concepção de língua (cf Bolinger1976, Fillmore, 1979, apud Kato, 1986), quanto no de aquisição (Nelson, 1974; apud Kato, 1986).

Mas o declínio de Skinner deve-se também a outro grande epistemólogo, Jean Piaget, para quem nehum conhecimento resulta apenas de estímulo externo, sem uma atividade estruturadora do sujeito. Nem esta pode ser constituída apenas por um mecanismo associativo, como era o caso do behaviorismo. Para este pensador, o que herdamos é uma inteligência sensório-motora para criar estruturas, através de ações organizadas sobre os objetos da aprendizagem. Esta inteligência sensório-motora pode ser estudada em seis estágios diferentes que são caracterizadas por esquemas de ação autoreguladas por correções, reforços, etc. A língua e outras funções semióticas começam nesse sexto estágio e se beneficiam das conquistas anteriores. Para Piaget, a lógica sensorial precede a lógica conceptual, da qual dependem o pensameno e a representação.

Embora Chomsky e Piaget se aproximem, por se oporem a Skinner, por ambos não acreditarem que a aquisição lingüística se dá principalmente em função do estímulo externo e através de uma mera capacidade associativa do homem, a grande diferença entre eles está na concepção do estado $\mathrm{S}_{\mathrm{o}}$, que para Piaget se limita a uma capacidade geral sensóriomotora $^{5}$ e para Chomsky à Gramática Universal (GU), a ser definida na próxima seção. Chomsky rebate a concepção piagetiana mostrando que há fatos comprovados que negam essa hipótese. Um exemplo que ele dá é o de crianças que nascem cegas e que, portanto, apresentam um sério deficit sensório-motor, mas que, no entanto, apresentam uma rapidez de aquisição até superior às de crianças com visão normal. Sabemos também que a linguagem de sinais, que substitui a língua falada para os surdos, apresenta propriedades e restrições sintáticas muito parecidas com as várias línguas conhecidas (cf. Klima, et alii,1979). Para Chomsky, a única condição para a aprendizagem de uma língua é ser humano e ser exposto a essa língua. Não há uma base sensório-motor multifuncional, que dê conta de diversos tipos de aprendizagem, incluindo a língua ${ }^{6}$.

\section{A VISÃO CHOMSKIANA DE APRENDIZAGEM (CHOMSKY, 1981, 1986, 1987, 1988, 1995)}

Vejamos primeiro o que não cabe na concepção de aprendizagem de Chomsky. Para Skinner e para Piaget, o mesmo esquema responde pela aprendizagem de várias habilidades/ capacidades. Para o primeiro é um mecanismo de associação e para o segundo é uma inteligência sensório-motora. Note-se que tais atributos não são restritos ao homem. No caso de Piaget, apenas o sexto estágio caracterizaria a diferença entre o homem e outros seres, no que diz respeito à aquisição da língua. Para Chomsky a criança vem dotada de um

\footnotetext{
${ }^{5}$ Cf. Piatelli-Palmarini, 1980.

${ }^{6}$ Para Inhelder (apud Chomsky, 1980), também da escola de Geneva, algumas, mas nem todas as propriedades da língua derivam de construções sensório-motoras, e Chomsky parece simpatizar bem mais com as idéias desse autor.
} 
KATO - A contribuição Chomskiana...

módulo da mente com capacidade especíalizada para aprender apenas línguas, e não outra coisa, e aprender língua independe de outras capacidades. Assim, a teoria lingüística Chomskiana adota uma perspectiva modular de Língua-I, postulando ser ela autônoma em relação a outros sistemas, que podem, como ela, estar envolvidos na Faculdade da Linguagem, ou o conjunto de conhecimentos que dão conta da produção e da compreensão. Isso é possível porque a Língua-I é o sistema computacional dessa faculdade, aquele que, a partir de uma coleção de itens lexicais constrói, entre outras, um par de representações estruturais interpretáveis nas interfaces. Uma das interfaces é a Forma Fonética (FF) e a outra a Forma Lógica (FL). Falando simplesmente, temos aí a relação som-significado. A FF faz a interface com os sistemas articulatório/perceptual e a FL faz interface com os sistemas conceitual/intencional (Chomsky, 1993).

Tanto Skinner quanto Piaget dão importância ao reforço para a aprendizagem. Para Chomsky, a criança é surda a correções. Ela só usa dados positivos, os que ela encontra na fala espontânea e não a dados negativos, providos por correção. Assim, os adultos raramente corrigem as formas produzidas pelas crianças , como mostra o exemplo de Brown (1973) com Adam
(1) Adam Where penny go?
Mother I don't know.
(2) Adam Where penny go?
Mother Didn't you drop your pennies on the floor?
(Adam, 2:5)

E quando o adulto tenta corrigir a criança, a correção não funciona, como mostra Braine (apud Pinker,1994:281):

(3) Child: Want other one spoon, Daddy.

Father: You mean, you want THE OTHER SPOON.

Child: yes, I want other one spoon, please, Daddy.

Father: Can you say "the other spoon"?

Child: Other...one...spoon.

Father: Say ...."other"

Child: Other.

Father: "spoon."

Child: Spoon.

Father: "Other Spoon."

Child: Other spoon. Now give me other one spoon?

Ao contrário do que muitos acreditam, o modelo chomskiano dá um papel importante aos dados ambientais, pois esses é que vão determinar o tipo de língua que a criança vai aprender. Mas para ele esses dados são espontâneos, fragmentados e não ordenados (do mais fácil para o mais difícil), como se acreditava na teoria do "motherese" ou do "baby talk". 
Para dar conta da questão de Plantão, "como a criança é capaz de aprender tanto e tão depressa diante de dados tão imperfeitos ?”, Chomsky (1986) responde que isso é possível

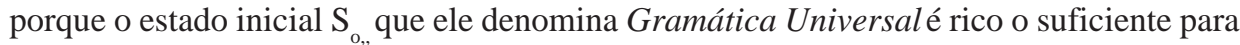
a criança atingir uma gramática em mais ou menos dois a três anos.

A Gramática Universal (GU) é postulada como o estado $\mathbf{S}_{\mathbf{0}}$ inicial, comum a todas as crianças, homogênea dentro da espécie humana. Longe de ser um estado vazio, a GU é definida como o conjunto dos Princípios ( $\mathbf{P 1}, \mathbf{P}_{2} \ldots . . \mathbf{P}_{\mathbf{n}}$ ), que regem todas as línguas naturais, e mais os Parâmetros $\left( \pm \mathbf{P a}_{1}, \pm \mathbf{P a}_{2}, \ldots \pm \pm \mathbf{P a}_{n}\right)$, que dão conta da variação interlinguística existente, concebidos como opções presentes ou ausentes[+ ou -]. Logo, uma boa parte da lingua a ser aprendida já está em $\mathrm{S}_{o}$, isto é, é inata, ou bio-prgramada. Os princípios não são aprendidos; quando muito maturam. Os parâmetros também já estão previstos, mas precisam ser definidos quanto ao seu valor [+ ou -], através do "input" que a criança recebe de sua comunidade ${ }^{7}$.

Para que essas noções fiquem mais concretas, vejamos alguns exemplos de Parâmetros

$\mathrm{Pa}_{1}$ Parâmetro do objeto nulo ( Uma língua pode permitir que o objeto esteja foneticamente nulo $\left[+\mathrm{Pa}_{1}\right]$, ou não $\left[-\mathrm{Pa}_{1}\right]$

(4) a. * I bought $Æ$ yesterday.

(inglês, $\left.\left[-\mathrm{Pa}_{1}\right]\right)$

b. * Yo compré Æ ayer.

c. Boku-ga kinoo $Æ$ kaimashita.

(japonês, $\left[+\mathrm{Pa}_{1}\right]$ )

$\mathrm{Pa}_{2}$ Parâmetro do sujeito nulo (Uma língua pode ter a possibilidade [+] ou não [-] do sujeito ser foneticamente realizado).

(5) a. *(He)Ate the pie.

b. (Él) Comió la torta.

(inglês, $\left[-\mathrm{Pa}_{2}\right]$ )

c, (Kare-ga) pai-o tabeta.

(espanhol, $\left.\left[+\mathrm{Pa}_{2}\right]\right)$

(japonês, $\left[+\mathrm{Pa}_{2}\right]$ )

$\mathrm{Pa}_{3}$ Parâmetro do movimento-wh. (Uma língua pode obrigar o movimento do elemento-wh (inglês) ou permitir que este fique in-situ (japonês)):

(6) a. What did Bill see _ ?

b. *Bill saw what?

c. Qué ha Juan visto?

d. *Juan ha visto qué?

e.. Biru-wa nani-o mita ka?

Bill top o que -acc viu interrogativo

(inglês, $\left[+\mathrm{Pa}_{3}\right]$ )

(espanhol, $\left.\left[+\mathrm{Pa}_{3}\right]\right)$

f. Nani-o Biru-wa mita ka?

${ }^{7}$ Para Chomsky, embora a língua-I seja um objeto interno ao indivíduo, uma comunidade que fala a mesma língua partilha o mesmo conhecimento linguíístico, isto é, apresenta línguas-I muito próximas.

${ }^{8}$ Essa ordem é, contudo, possível, como pergunta-eco, mas não como pergunta autêntica. 
KATO - A contribuição Chomskiana...

$\mathrm{Pa}_{4}$ Parâmetro do movimento do verbo para Comp ( Uma língua pode exigir o deslocamento do verbo flexionado para antes do sujeito em interrogativas-wh com movimento-wh, ou não)

(7) a. What had John seen?

b. *What John saw?

c. Qué habia Juan visto?

d. *Qué Juan habia visto?

e. Nani-o Juan-wa mita-ka?

f. *Nani-o mita Juan-wa ka?

(inglês, $\left.+\mathrm{Pa}_{4}\right]$ )

(espanhol, $\left.\left[+\mathrm{Pa}_{4}\right]\right)$

(japonês, $\left[-\mathrm{Pa}_{4}\right]$ )

Consideremos apenas esses Princípios e Parâmetros. A criança inglesa, espanhola, e japonesa apresentam, no estágio inicial $\mathrm{S}_{\mathrm{o}}$, o mesmo "conhecimento" (GU), no qual os parâmetros ainda estão indefinidos [ $[ \pm]$ :

(8) $\mathrm{GU}=\mathrm{S}_{\mathrm{o}}:\left(\mathrm{Pr}_{1}, \mathrm{Pr}_{2}, \ldots \ldots\right)\left(\left[ \pm \mathrm{Pa}_{1}\right],\left[ \pm \mathrm{Pa}_{2}\right],\left[ \pm \mathrm{Pa}_{3}\right],\left[ \pm \mathrm{Pa}_{4}\right] \ldots\right)$

O que ocorre na aquisição dessas crianças:

- na língua-I dos adultos a que as crianças estão expostas, os parâmetros aparecem todos marcados [+] ou [- ];.

Língua-I de um Inglês

Língua-I de um espanhol:

$$
\begin{aligned}
& {\left[\mathrm{Pr}_{1}, \mathrm{Pr}_{2}, \ldots \mathrm{Pr}_{\mathrm{n}}\right]\left[-\mathrm{Pa}_{1}\right],\left[-\mathrm{Pa}_{2}\right],\left[-\mathrm{Pa}_{3}\right] \cdot\left[+\mathrm{Pa}_{4}\right] \ldots . .} \\
& \left.\left[\mathrm{Pr}_{1}, \mathrm{Pr}_{2}, \ldots \mathrm{Pr}_{\mathrm{n}}\right]-\mathrm{Pa}_{1}\right],\left[+\mathrm{Pa}_{2}\right]\left[-\mathrm{Pa}_{3}\right],\left[+\mathrm{Pa}_{4}\right] \ldots . \\
& {\left[\mathrm{Pr}_{1}, \mathrm{Pr}_{2}, \operatorname{Pr}_{\mathrm{n} .}\right]+\mathrm{Pa}_{1},\left[+\mathrm{Pa}_{2}\right],\left[+\mathrm{Pa}_{3}\right] \cdot\left[-\mathrm{Pa}_{4}\right] \ldots}
\end{aligned}
$$

Língua-I de um Japonês

- a aquisição é um processo de seleção do valor + ou - desses parâmetros, que a criança depreende dos dados positivos produzidos por esses adultos (exemplos em (4) a (7).

O que podemos dizer é que ocorre um processo semelhante ao que ocorre na fonologia. Da mesma forma que a criança no início do balbucio é capaz de produzir qualquer som humano e depois vai restringindo o universo dos sons aos sons que ela ouve no ambiente, a criança, no início, "sabe" todos os valores dos parâmetros (é uma poliglota latente), mas ao ser exposta aos dados do ambiente vai eliminando uma das opções dos parâmetros.

A concepção inicial de "parâmetro" é que ele constitui uma propriedade que é responsável por um ou mais tipos concretos de construção. Um exemplo ortodoxo, já bastante questionado, é o parâmetro do "sujeito nulo". A propriedade que dá conta das construções desse parâmetro é um traço abstracto. que não vem ao caso discutir aqui, traço este que seria responsável por?

${ }^{9}$ O Português Brasileiro vem perdendo essas propriedades. Logo, os exemplos são do Português Europeu (EP). 
a) sujeitos ocultos pronominais: ( Pedro disse que (ele) caiu)

b) extração do sujeito a longa distância (Quem ${ }_{i}$ Maria disse que _ ${ }_{i}$ viu Pedro?)

c) sujeito posposto (Telefonou um cliente)

Esse tipo de concepção permite supor que a criança não precisa ser exposta a todas as construções que o valor do parâmetro prediz. Algumas poderiam ser dedutivamente adquiridas e isso responderia ao problema lógico da aquisição.

Mas as gramáticas assim adquiridas, via seleção do valor do parâmetro, são virtuais para Chomsky, que as chama de gramáticas nucleares. Toda língua-I teria esse núcleo, mas também uma periferia marcada que pode ser distinta de indivíduo para indivíduo. Por exemplo, uma criança que cresceu em ambiente bilíngüe pode ter uma periferia marcada distinta de uma criança monolíngüe. Voltaremos a essa questão na última seção.

Em suas perguntas de aquisição, Chomsky aborda apenas a natureza do estado inicial $\mathrm{S}_{\mathrm{o}}$ ( ou GU) e do estado terminal (língua-I), nada comentando ou propondo sobre as etapas de desenvolvimento; em outras palavras, como e quando os parâmetros são definidos.

Mas os psicolingüistas gerativistas tem outras perguntas que querem ver respondidas:

a) há um período pré-sintático, iso é, a GU está accessível desde o início?

b)os dois valores do parâmetro tem estatuto igual? ou um deles seria o 'default', a hipótese que a criança usa na ausência de uma pista segura?

Em relação à primeira questão, duas tendências principais podem ser identificadas:

a) a que postula uma fase pré-sintática ( Bickerton,1990, entre outros) e

b) a que advoga que desde o início a criança apresenta uma estrutura sintática que se conforma com os princípios e/ou as categorias que regem a gramática do adulto (Hyams, 1986, entre outros).

Na visão dos que se encaixam na primeira tendência, os maturacionistas, a linguagem da criança, nessa fase, é uma forma de comunicação que pode envolver o módulo pragmático/semântico da linguagem, mas não o conhecimento gramatical.

Na visão do segundo grupo, os continuistas, a linguagem primitiva da criança já é constrangida por princípios da GU e pelo valor não-marcado dos parâmetros, já respondendo, assim, à segunda questão. O valor não-marcado, ou 'default', seria o que determinaria operações mais econômicas. Isso significa que a criança pode reassentar o valor do parâmetro quando vê que os dados ambientais diferem de sua primeira hipótese. Essa perspectiva postula, portanto, a acessibilidade de GU desde o início.

Para ilustrar essa querela, tomemos as seqüências sem palavras funcionais e sem flexão produzidas por crianças aprendendo diferentes línguas. Para alguns, elas seriam produzidas pelas crianças por que elas ainda não teriam acesso à GU. Para Bickerton elas seriam similares a construções "pidgin", e constituem proto-gramáticas. Essas mesmas construções têm sido vistas por outros (Radford, 1990, Lebeaux,1990, Guilfoyle and 
KATO - A contribuição Chomskiana...

Noonan, 1988) como formas sintáticas de natureza léxico-temática, uma subparte da estrutura-P do adulto. Seria a tese do truncamento, segundo a qual crianças pequenas falam através de orações pequenas (mini-orações) ou de subpartes da gramática do adulto. Mas ambas as interpretações são concepções maturacionistas, por admitirem que a minigramática (ou a proto-gramática) da criança é diferente da do adulto.

$\mathrm{Na}$ visão dos continuistas, por outro lado, a aparente fase léxico-temática oculta categorias funcionais, visíveis em certas regularidades na produção da criança. A diferença de posição da negação em frases truncadas com verbo no infinitivo ("pas manger") e com tempo finito ("mange pas") seria uma pista para dizer que a categoria Tempo já está na gramática da criança. Alguns desses continuistas atribuem o aparente truncamento à limitações de processamento: a criança corta um pedaço da frase por limitações de articulaçaõ ou de percepção (Bloom, 1990, entre outros).

\section{OS TRABALHOS SOBRE L2 NA PERSPECTIVA CHOMSKIANA}

No período anterior à decada de 80 , iso é, ao advento do modelo de Princípios $e$ Parãmetros, havia uma tendência a se acreditar que a aprendizagem de L2 era um fenômeno distinto de L1. Com a Análise Contrastiva, no estruturalismo, que estudava principalmente as diferenças entre L1 e L2, procurava-se predizer onde estariam as regiões de dificuladade, transferência e erros na aprendizagem. Krashen (1982) introduz a distinção entre aquisição e aprendizagem, a primeira para dar conta do processo inconsciente que caracteriza a evolução de L1 e a segunda, que envolve processos metalingüísticos de aprendizagem de "regras" ${ }^{10}$. Mesmo na década de 80 encontram-se adeptos dessa visão, como, por exemplo, Bley-Vroman (1989), para quem a aprendizagem de L2 se basearia em operações cognitivas, do tipo Piagetiano, hipótese esta fortemente contestada por Epstein (1996), para quem é impossível atingir o conhecimento de uma gramática apenas com princípios não-gramaticais.

Mas já antes de Princípios e Parâmetros, ainda na década de 70, faz-se sentir a influência indireta de Chomsky, através justamente daqueles que procuraram analisar os "erros" com o fim de mostrar que eles não derivavam necessariamente de trasferência de L1, mas de algum processo criativo, que viria do acesso à GU (Corder, 1967; Burt and Dulay, 1972; Selinker, 1972).

A pesquisa em L2 dentro do modelo de Princípios e Parâmetros enfatiza as questões teóricas, procurando seguir a forma de indagação científica que Chomsky usa para a aquisição de L1. Para a L1 Chomsky mostra que a resposta explicativa de sua teoria estaria na aqusição, a saber, a resposta à pergunta: "como a criança , partindo de GU, chega à sua língua-I"? Essa pergunta envolve, portanto, duas pergutas anteriores:

\footnotetext{
${ }^{10}$ Mesmo Meisel (1997), um gerativista convicto faz essa distição. Para ele, aprendizagem requer exposição mais freqüente ao input, por um período maior de tempo, com exemplos salientes e não ambíguos.
} 
a) qual é a forma da língua-I de um inglês, de um espanhol, de um japonês, etc?

b) qual é a forma da GU, isto é, qual o saber sobre as línguas naturais que todas as crianças já trazem geneticamente?

A resposta dada no princípio da década de 80 (Chomsky, 1981, 1986) foi o Modelo de Princípios e Parâmetros, que vimos simplificadamente acima ${ }^{11}$.

O psicolinguista da área de L2 parte então para as mesmas questões. Tomando, por exemplo, a língua inglesa como o conhecimento a ser atingido como L2, por um aprendiz espanhol ou japonês, o pesquisador teria dois caminhos a escolher:

a) supondo que a aprendizagem de L1 e de L2 partam do mesmo estado inicial $\mathrm{S}_{\mathrm{o}}$ (=GU), verifica-se se a aprendizagem segue o mesmo caminho de uma criança aprendendo inglês como L1.

b) supondo que o aprendiz parte de seu conhecimento já adquirido de uma língua primeira, seja o espanhol ou o japonês, verifica-se se esse conhecimento tem algum papel na aprendizaggem.

Essas perguntas se resumem, portanto, na pergunta: qual o estado $S_{0}$ da aquisição de L2? Duas hipóteses têm sido consideradas:

a) a primeira diz que o estado inicial é o mesmo de uma criança aprendendo sua primeira língua, isto é, seria a GU. Se, além disso, aderirmos à hipótese de que há um valor 'default' que serviria de hipótese nula, o aprendiz de L2 começaria com o valor 'default' dos parâmetros, isto é, aquele que envolve menos custo derivacional.

b) a segunda diz que o estado inicial apresenta as mesmas seleções dos valores dos parâmetros da Língua-I do sujeito, apenas recheado do léxico da L2, devendo haver, portanto, uma boa dose de transferência. Esta hipótese segue a tradição dos estudos de L2 antes da gerativa, mas tem ressurgido na própria gerativa em diferentes roupagens (hipótese da "Full transfer" (Schwartz \& Sprouse 1996), hipótese da "Arvore mínima" (cf Vainikka $\&$ Young-Sholten, 1996, para citar os mais conhecidos). Mas o problema dessa abordagem é que o aprendiz terá que eventualmente recorrer a valores paramétricos que não fazem parte das opções de sua L1. Um americano aprendendo o português, poderá começar preenchendo sempre o objeto, como em inglês, mas se ele aprende efetivamente a gramática do português, deverá começar a usar nulos em contextos relevantes. Poderíamos pensar que isso é relativamente fácil pois se trata de uma propriedade que pode ser o resultado apenas de um apagamento fonético. Lembremos, porém, que o objeto nulo seria apenas uma das manifestações de uma propriedade mais abstrata, que licencia também outras construções. De fato, línguas de objeto nulo não licenciam apenas objetos nulos, mas exibem outras características (cf Raposo, 1998): a) artigos nulos como em (9)a e núcleos nominais nulos, como em (9)b.

\footnotetext{
${ }^{11}$ Para informações sobre a fase mais recente minimalista, consulte-se Lopes (2001).
} 
KATO - A contribuição Chomskiana...

(9) a. O João adora cenoura.

b. O Pedro comprou o carro azul e o João o__ vermelho.

Só poderíamos afirmar que o americano remarcou apropriadamente o parâmetro do objeto nulo se apresentar o conjunto de propriedades que se aprende através da definição de um valor de parâmetro. Além disso, algumas dessas propriedades seriam dedutivamente aprendidas, não necessitando de exposição direta a elas.

Tomemos o caso de um espanhol aprendendo as interrogativas do inglês. Note-se que, nos dois parâmetros relevantes (Movimento-wh e V-para Comp), a L1 e a L2 tem a mesma marcação. Para a corrente que advoga que são os valores paramétricos de L1 que atuam na aprendizagem, teríamos a previsão de que a aprendizagem nos dois aspectos seria instantânea para o falante do espanhol. Mas se a outra corrente estiver correta, teremos nos aprendizes espanhóis uma fase inicial em que nem o elemento-wh e nem o verbo flexionado se moveriam para antes do sujeito, havendo a produção de formas como (10), agramaticais no inglês. ${ }^{12} \mathrm{~A}$ forma (10) se conforma a uma gramática possível nas línguas naturais, o PB, por exemplo (exemplo (11)), mas não pode ser atribuída à L1 do falante espanhol:

(10) *John saw what yesterday?

(11) João viu quem ontem?

Esse tipo de ocorrência seria uma pista fundamental para corroborar uma ou outra teoria.

Por outro lado, se o aprendiz é japonês, cuja L1 tem marcação oposta aos valores do inglês nos dois parâmetros, a produção de uma sentença como (10) nada revela sobre seu estado $S_{0}$. Ele tanto pode estar usando a gramática de sua L1, o japonês, que não tem nem movimento-wh obrigatório e nem movimento do verbo para Comp, como também pode estar usando os valores 'default' desses dois parâmetros, a saber, os que não requerem movimento.

Mas a hipótese do estado $\mathrm{S}_{0}=\mathrm{L} 1$ tem a tarefa de explicar como o aprendiz japonês eventualmente chegará a produzir (12), em conformidade com os valores paramétricos do inglês.

(12) What did John see yesterday?

Essa hipótese terá que usar a GU para propor que o aprendiz muda os valores desses parâmetros.

Se aceitarmos como hipótese verdadeira que a aquisição de L2 se baseia em acesso à GU, como a L1, por que esta é tão fácil e a L2 não é? A resposta está na modularidade da

${ }^{12}$ Tal tipo de frase é só admissível no inglês como pergunta-eco, mas, nesse caso, o elemento-wh está quase sempre no final da sentença. 
faculdade da linguagem. O módulo específico da gramática não dá conta sozinha da compreensão e da produção. Esta envolve capacidades pragmáticas, semânticas, conhecimento lexical etc. A fluência e a proficiência dependem desse conjunto de capacidades e a forma como elas interagem. Menciono, em outro trabalho, (Kato, 2003) que sou falante de japonês como L1, mas hoje minha fluência está terrivelmente deteriorada, principalmente porque perdi, por falta de uso, uma grande parte do léxico substantivo. Mas sou capaz de dar julgamentos de gramaticalidade sobre frases extremamante complexas, capacidade essa que se deve apenas ao componente computacional da língua, isto é, à minha língua-I.

As hipóteses possíveis sobre aprendizagem de L2 foram apresentadas de forma simplificada e superficial neste trabalho. O que quisemos mostrar com elas é que a contribuição chomskiana para a área é sobretudo para a pesquisa teórica no entendimento dessa aprendizagem. As questões são rigorosamente formuláveis de tal forma que os dados possam ser interpretados dentro de cada hipótese.

Podemos inferir ainda algumas contribuições práticas a partir de suas idéias sobre aprendizagem lingüística:

a) a aprendizagem espontânea de L1 se dá por exposição a dados somente positivos (correções não têm lugar); mostrar o que é errado não teria efeito nem para L1 e nem para L2;

b) na aquisição de L1 o input não é ordenado; pode-se dizer o mesmo de aprendizagem de L2 por imersão, mas não da maioria das situações de aprendizagem formal;

c) a gramática da L1 não se adquire por estímulo, resposta e reforço; o mesmo é válido para L2;

d) a aquisição de uma gramática não tem por base a inteligência sensório-motora. A aprendizagem de L2 em geral se dá depois do sexto estágio. Logo, se Piaget estivesse certo, deveria ser mais fácil aprender L2 do que L1, mas sabemos que não é.

Termino esta exposição com as palavras sobre L2 do próprio mestre, na sessão de perguntas e respostas do livro The Managua Lectures

Question: A child can learn two languages simultaneously, one in the house and the other in the street. Does that mean that the child relates the position of the switches to the environment?

Answer: Well, this is a very important question which I have been pretending all along does not arise. The question is a very mysterious one, because the child learns different languages, say Spanish at home and English in the streets. But, in fact, the problem is really more general, because every human being speaks a variety of languages. We sometimes call them different styles or different dialects, but they are really different languages, and somehow we know when to use them, one in one place and another in another place. Now each of these different languages involves a different switch setting. In the case of Spanish/English it is a rather dramatically different switch setting, more so than in the case of the different styles of Spanish that each of you has mastered. (Chomsky 1988: 188) 
KATO - A contribuição Chomskiana...

\section{REFERENCIAS BIBLIOGRÁFICAS}

BICKERTON, D. (1981). Roots of language.AnnArbor: Karoma Publishers.

BEVER, T. G. (1970). The cognitive basis for linguistic structures. In: J.R.Hayes (org) Cognition and the developmente of language. New York: John wiley \& sons.

BLOOM, P. (1990). Subjectless sentences in child language , LI 21(4): 491-504.

BROWN, R. (1973). A First language: the early stages.Cambridge, Mass: Harvard University Press.

DULAY, H.C., BURT, M. K. \& KRASHEN, S. (1982). Language two. New Your: Oxford University press.

CELANI, M. A. A. \& PASCOAL, M. S. Z.de. (1992). Linguística Aplicada: da Aplicação da Lingüística para uma Lingüística Transdisciplinar. São Paulo: EDUC.

CHOMSKY, N. (1959). A review of B.F. Skinner's Verbal Behavior. Language,35:1: 26-58.

(1981). Lectures on Governmente and Binding.Dordrecht:Foris.

(1986a) Knowledge of language. New York: Praeger.

(1987) On the nature, use and aquisition of language:Kyoto Lectures I, ms.

(1988) Language and problems of Knowledge: The Managua Lectures. Cambridge,Mass: The MIT Press.

(1995) The Minimalist Program Cambridge, Mass: The MIT Press.

CORDER, P. (1967). The significance of learner's errors'. International Review of Applied Linguistics, 5: 161170.

EPSTEIN, S. D. \& G. (1996). Second language acquisition: theoretical and experimental issues in cntemporary reseearch. behavioral and Brain Sciences, 19(4): 677-758.

FELIX S. (1987). Cognition and Language Growth. Dordrecht: Foris.

GUILFOYLE, E \& NOONAN, M. (1992). Functional categories and language acquisition. The Canadian Journal of Linguistics,37: 241-272.

HALLIDAY, M. A. K. (1975). learning how to mean: explorations in the development of language. Londres: Edward Arnold.

HYAMS, N. (1986). Language Acqusition and the Theory of Parameters. Dordrecht: Reidel.

KATO, M. A. (1986). no Mundo da Escrita. São Paulo: Editora Ática. (2003). Child L2 acquisition: an insider account. In: Natascha Müller. (ed) (In)vulnerable domains in Multilingualism, John Benjamins. 271293.

KLIMA, E., BELLUGI, U. et al. (1979). The signs of language. Cambridge/London: Harvard University Press.

KRASHEN, S. (1982). Principles and Practices of Second language Acquisition. Oxford: Pergamon.

LEBEAUX, D. (1988). Language Acquisition and Form of Grammar. MIT: PH.D.Dissertation.

LOPES, R. V. (2001). Aquisição da linguagem: novas perspectivas a partir do programa Minimalista. DELTA, 17,2:245-281. 
Trab.Ling.Aplic., Campinas, 44(2) - Jul./Dez. 2005

MEISEL, J. (1997). The acquisition of the syntax of negation in French and german: contrasting first and second language development. Second Language Research, 13, 3: 227-263.

NEWMEYER,F. J. (1983). Grammaical Theory:its limits and possibilities.Chicago: The University of Chicago press.

PIATELLI-PALMARINI, M. (1980). (org). From Language and learning: the Debate between Jean Piaget and Noam Chomsky. Cambridge, Mass: Harvard University Press.

PINKER, S. (1994). The language Instinct. new Yourk: William Morrow and Co, Inc.

RAPOSO, E. (1998). Dfinite/zero Alternations in Portuguese "Romance Lingusitics: Theoretical Perspectives,", ed. by A.Schwegler, B Tranel \& M. Uribe-Etxebarria, 197-212. John Benjamins. Amsterdam \& Philadelphia.

SKINNER, B. F. (1957). Verbal Behavior. New York: Appleton-Century-Croft.

SLOBIN, D. (1980). Psicolingüística. São Paulo: Ed. Nacional.

RADFORD, A. (1990). Syntactic Theory and the Acquisition of English Syntax. Oxford: Basil Blackwell.

SCHWARTZ,B. D. \& SPROUSE, R. A. (1996). L2 cognitive states and the full transfer/full access model. Second Language Research 12, 40-77.

SELINKER, L. (1972). Interlanguage International Review of Applied Linguistics,10:209-231.

VAINIKKA \& YOUNG-SHOLTEN. (1996). Gradual development of L2 phrase structure. Second Language Research 12: 7-39. 